$$
\begin{aligned}
& \text { ؤركم آمنربتول }
\end{aligned}
$$

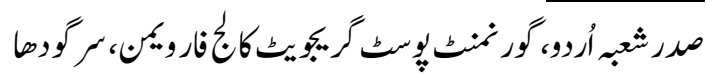

$$
\begin{aligned}
& \text { سيَ ازورعباس }
\end{aligned}
$$

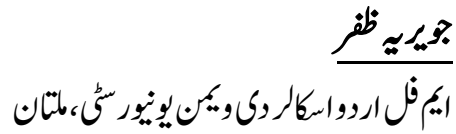

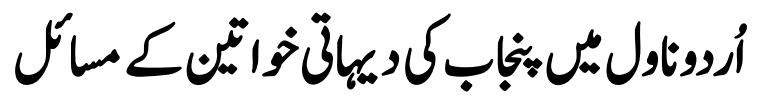

Dr. Amna Batool

Head Deptt of Urdu, Govt Post Graduate College For Women, Sargoda

Syed Azwar Abbas

Lecturer Urdu, Hazara University, Mansehra

Jawaria Zafar

Mphil Urdu Scholar, The Women University Multan.

\title{
Problems of Rural Women of Punjab In Urdu Novel
}

Women has a vital role in human society. Women are playing important tasks all over the world. Despite of the facts, women are still facing unfavorable environment especially in our rural areas. This situation reveals that woman of our society has limited opportunities to move forward. Although overall circumstances are changing with the passage of time, but there is much to do, particularly in rural areas for acceleration of woman role.

Keywords: Punja6, Rural Women Problems, Novel.

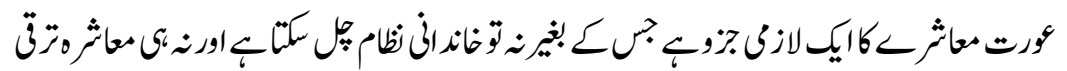

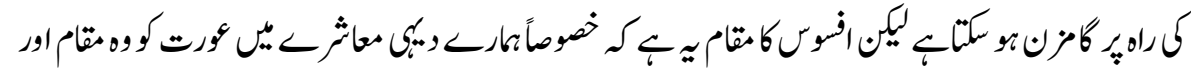

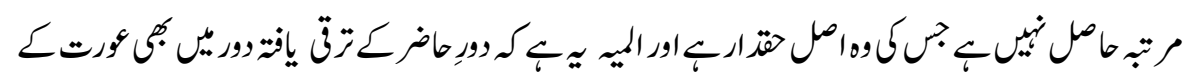

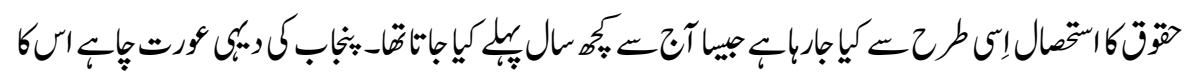

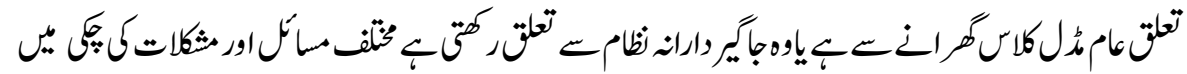


ISSN (Print): 2709-9636 | ISSN (Online): 2709-9644

Volume 2, 2021(Issue III, July to September)

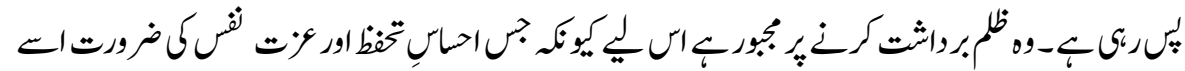

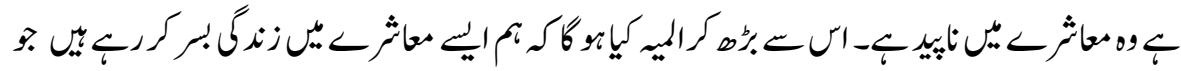

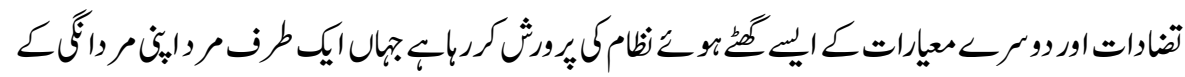

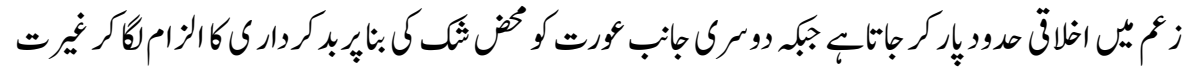

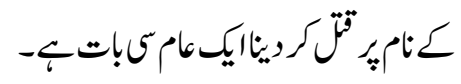

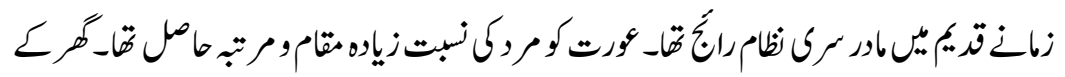

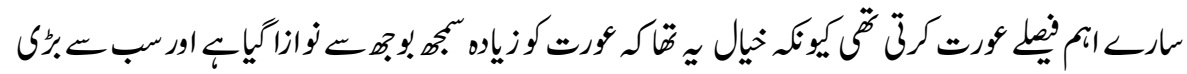

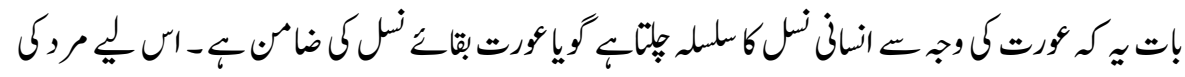

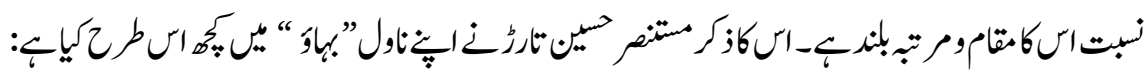

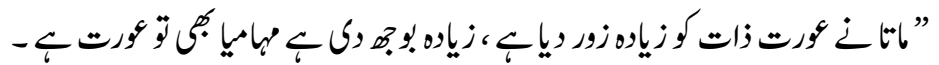

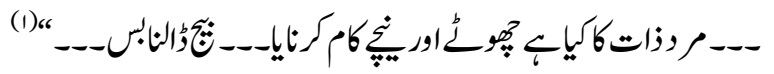

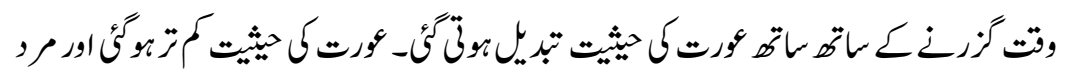

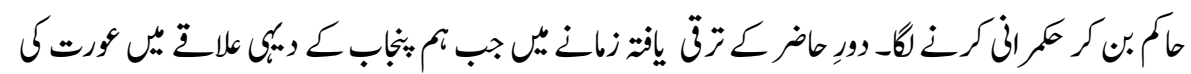

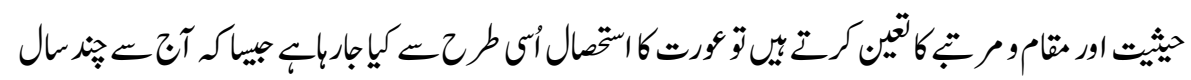

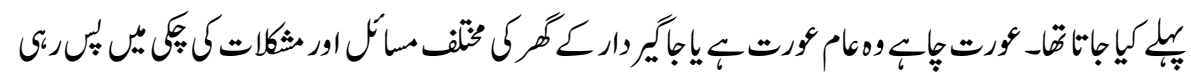

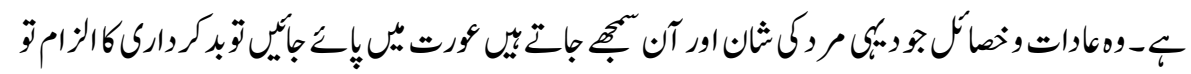

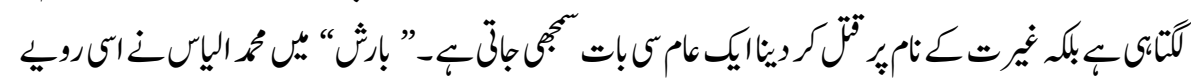
كم

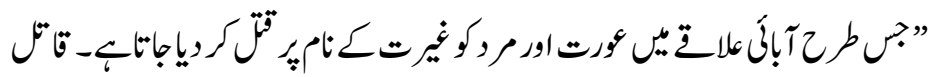

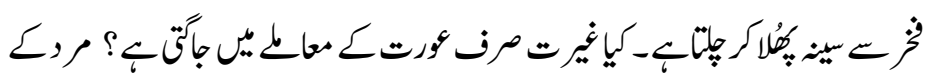

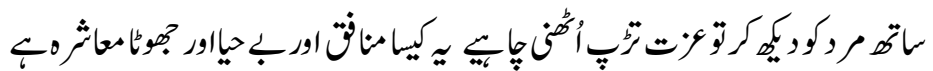

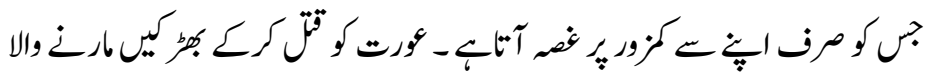

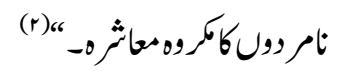




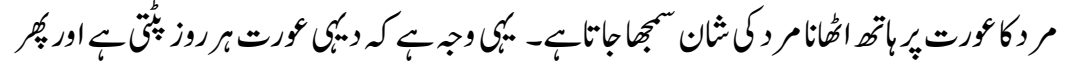

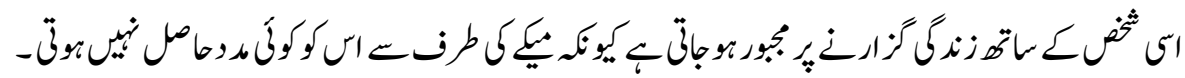

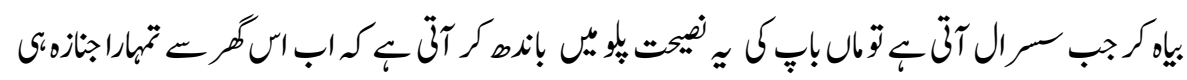

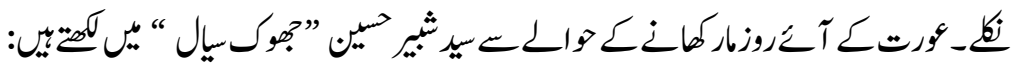

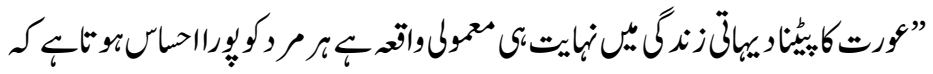

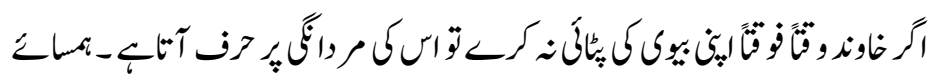

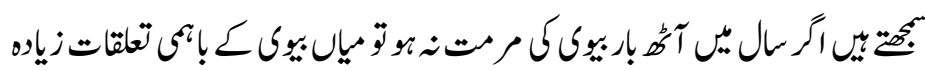

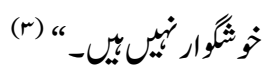

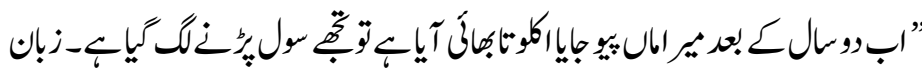

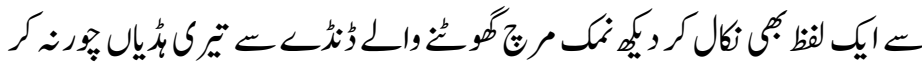

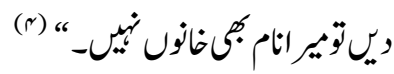

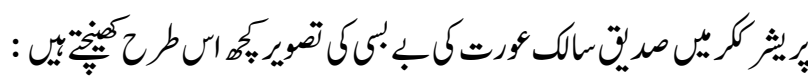

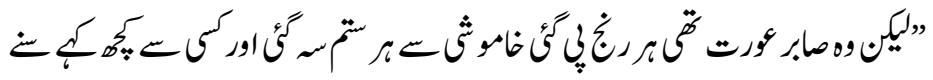

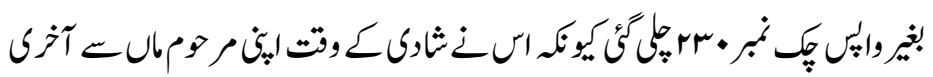

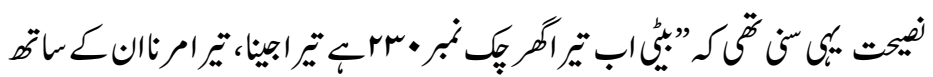

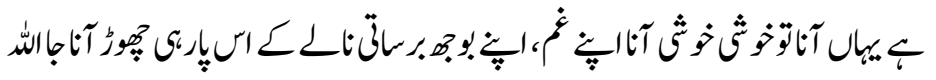

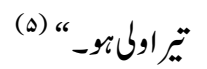

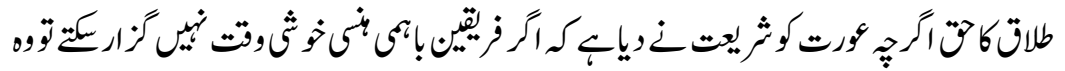

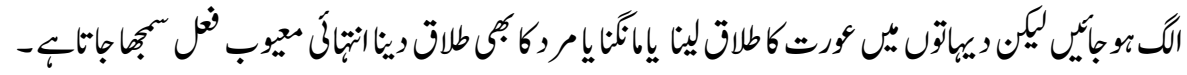

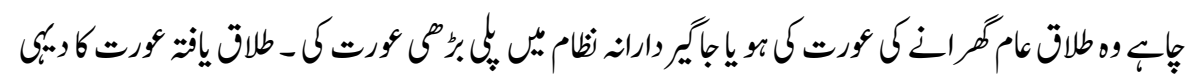

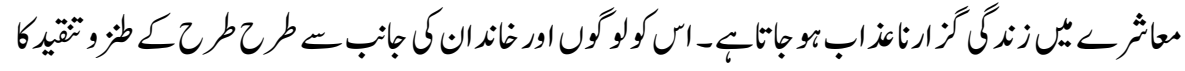

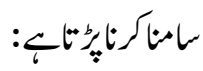


ISSN (Print): 2709-9636 | ISSN (Online): 2709-9644

Volume 2, 2021(Issue III, July to September)

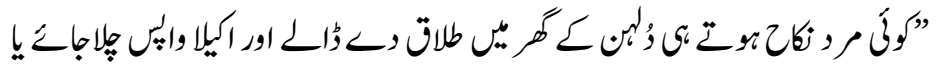

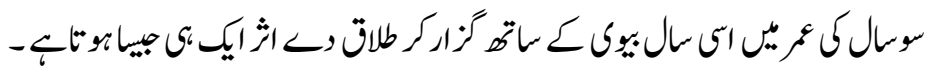

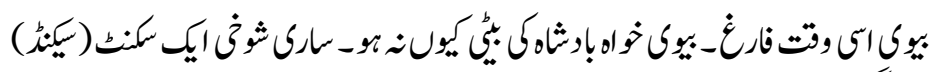

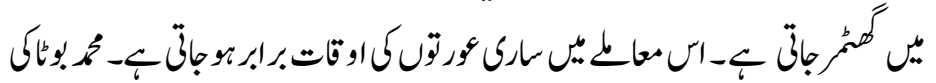

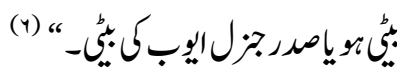

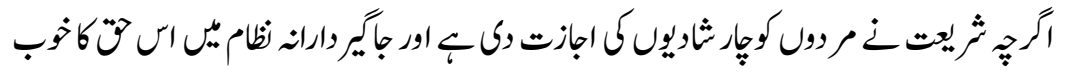

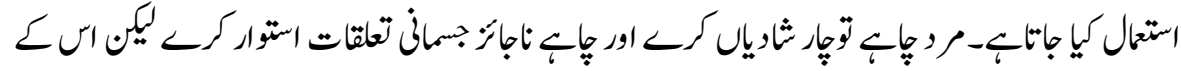

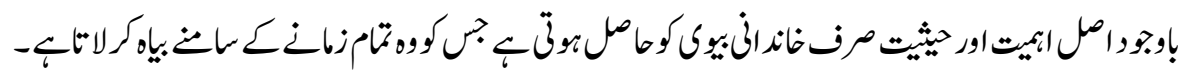

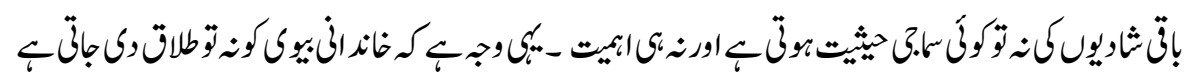

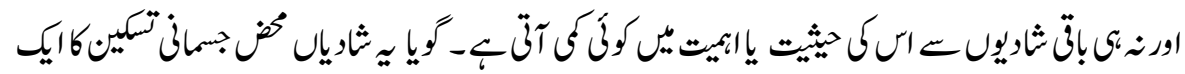

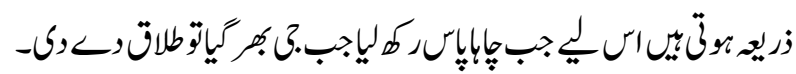

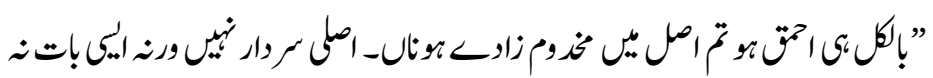

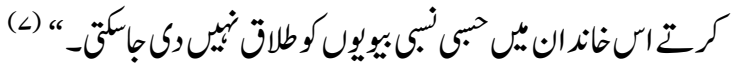

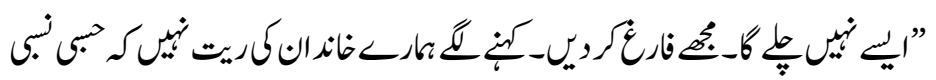

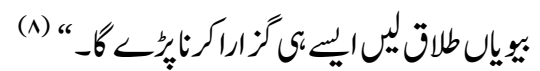

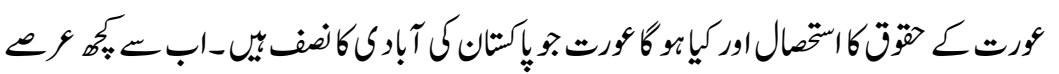

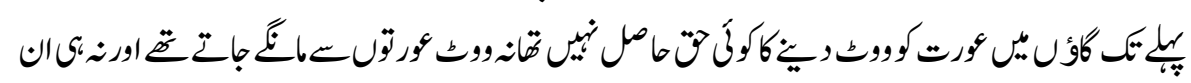

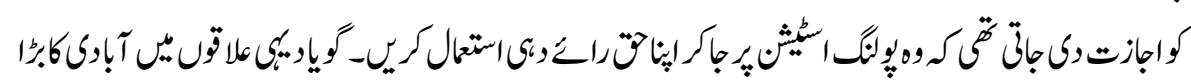

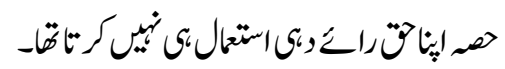

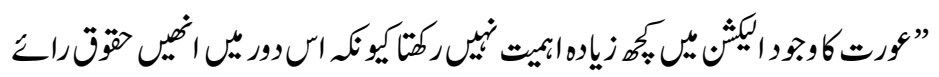

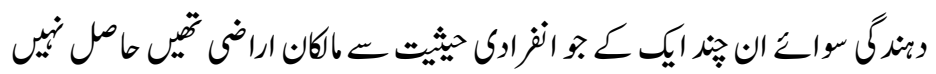

(9)، $-\ddot{E}$ 
ISSN (Print): 2709-9636 | ISSN (Online): 2709-9644

Volume 2, 2021(Issue III, July to September)

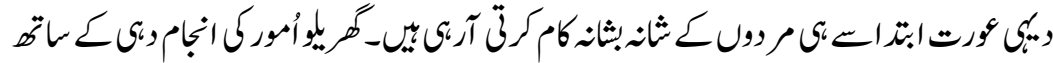

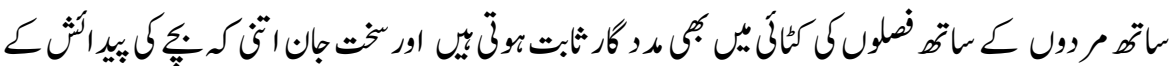

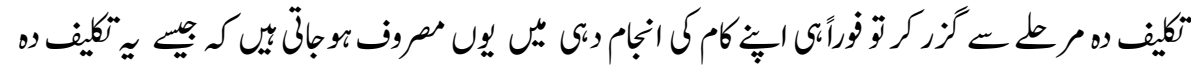

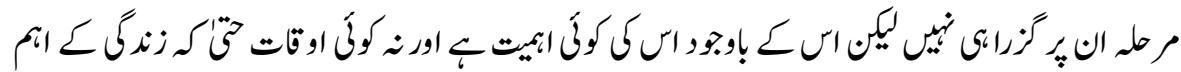

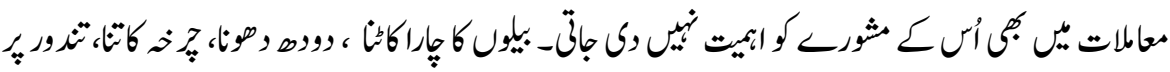

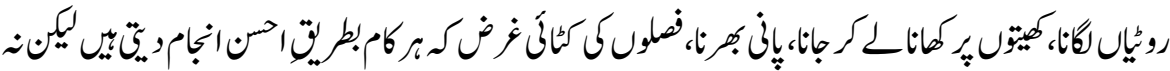

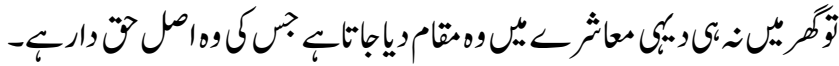

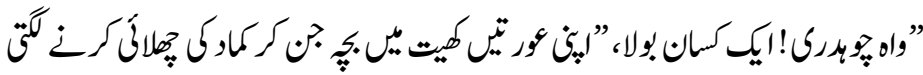
(1.) “ ".

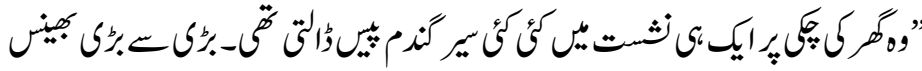

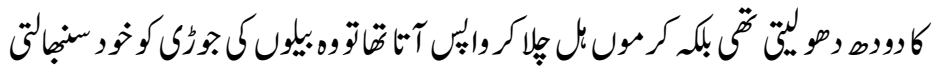

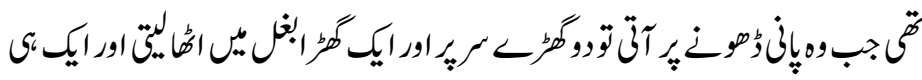

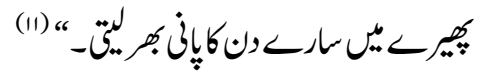

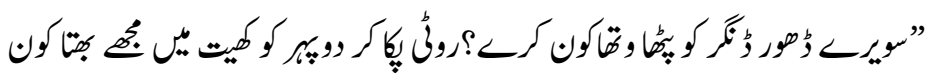

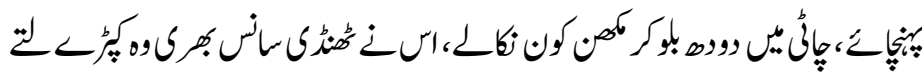

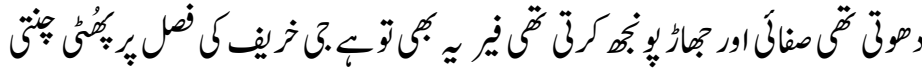

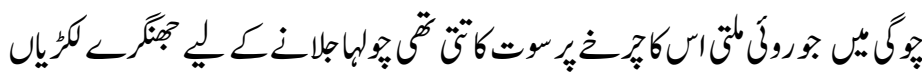

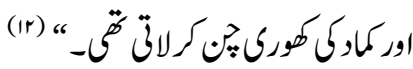

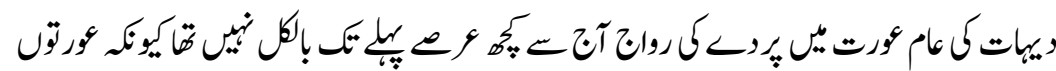

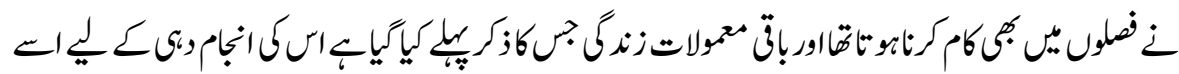

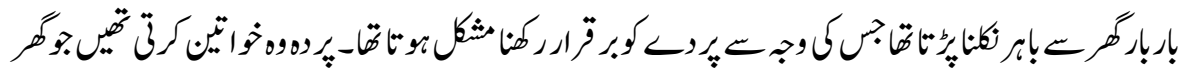

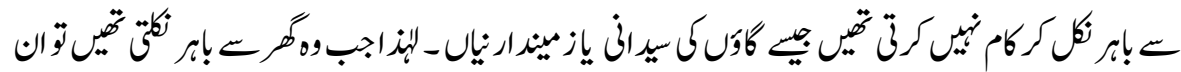

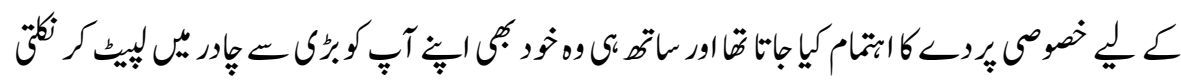




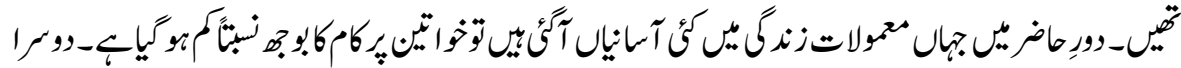

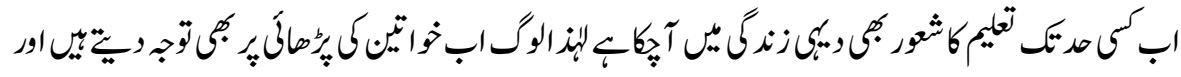

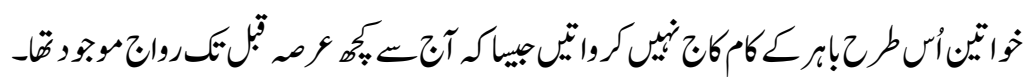

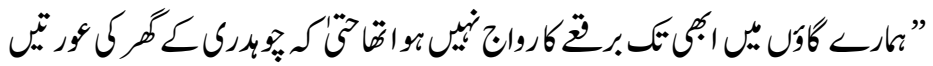

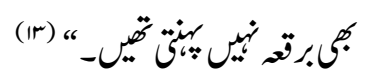

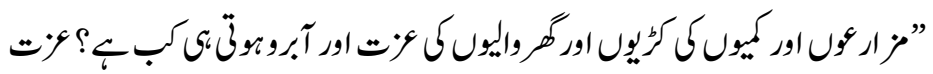

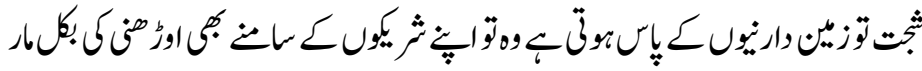

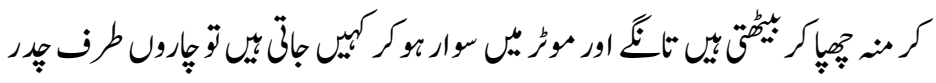

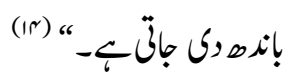

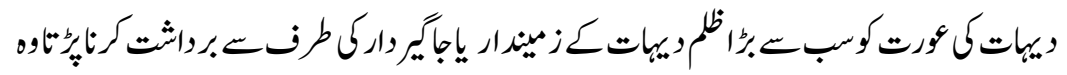

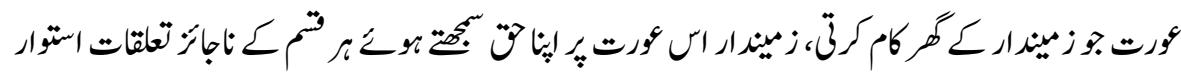

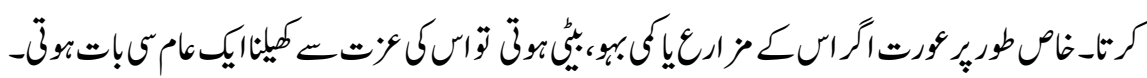

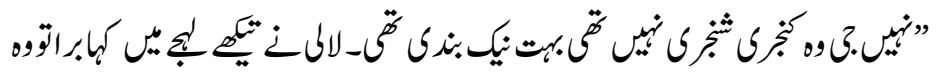

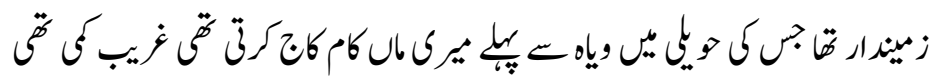

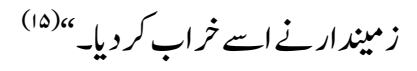

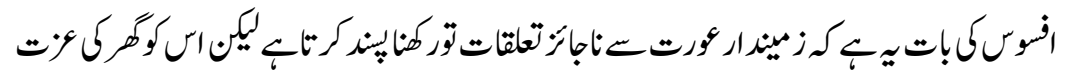

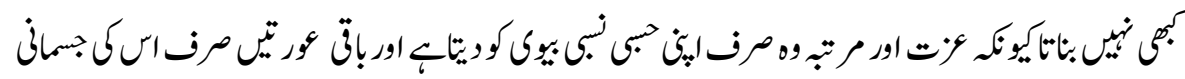

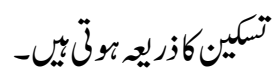

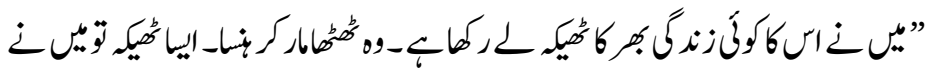

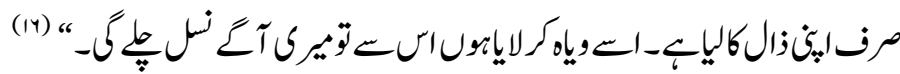

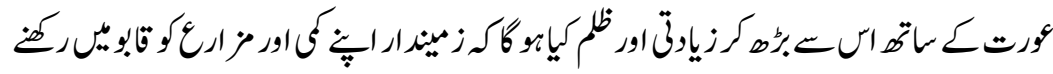

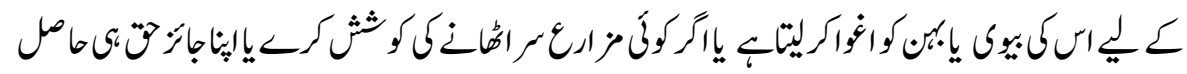




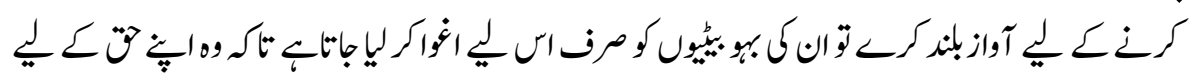

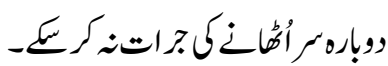

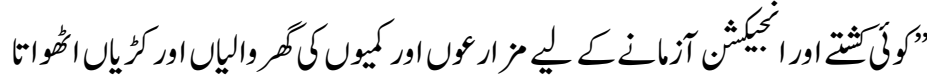

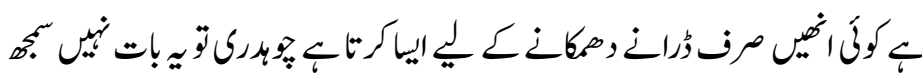

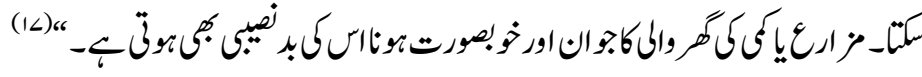

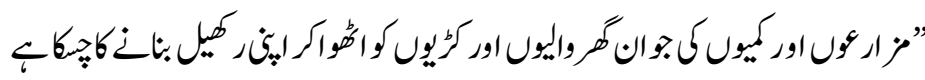

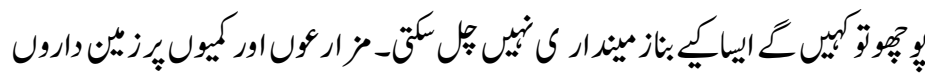

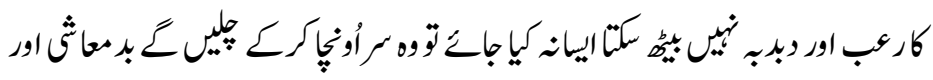

$$
\text { (11) }
$$

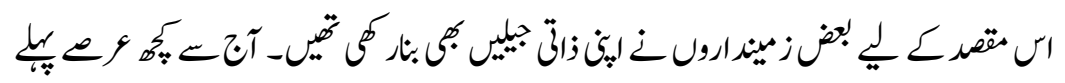

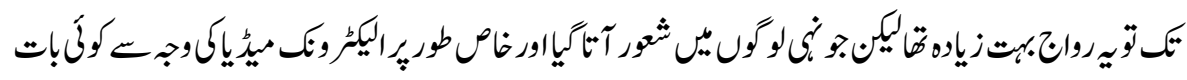

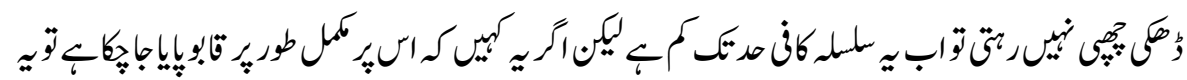

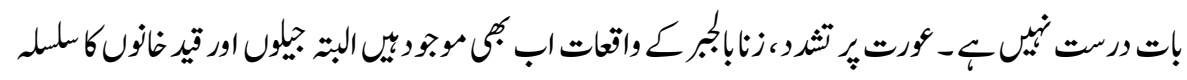

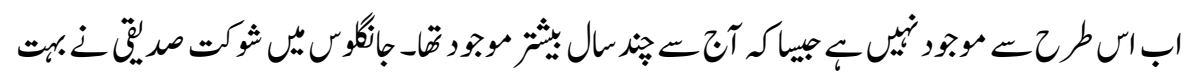

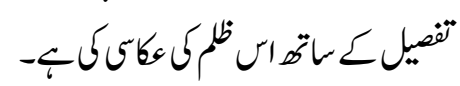

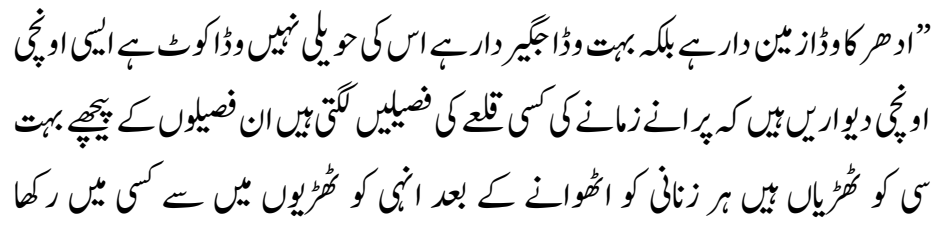
(19) “ $-<6$

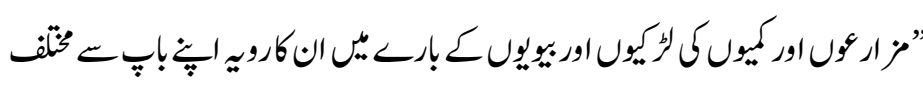

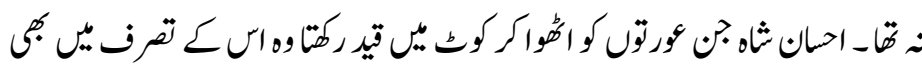

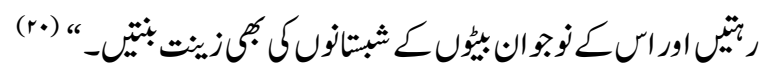




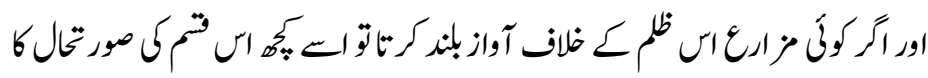

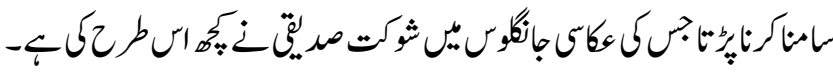

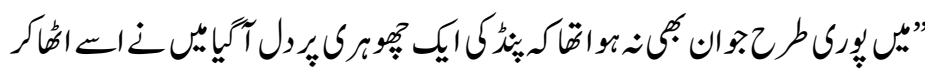

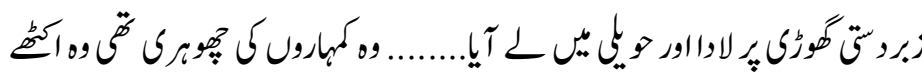

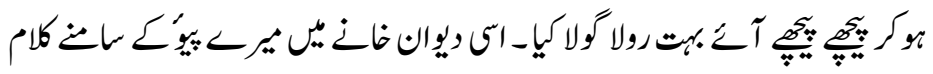

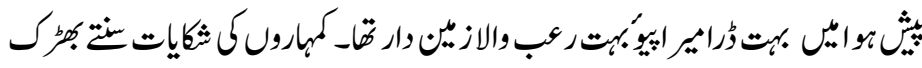

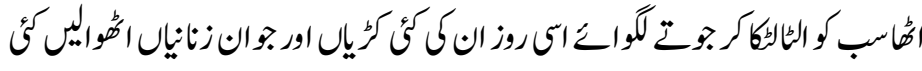

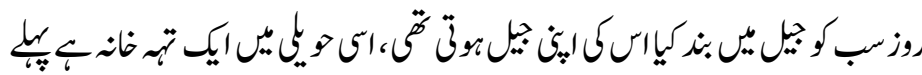

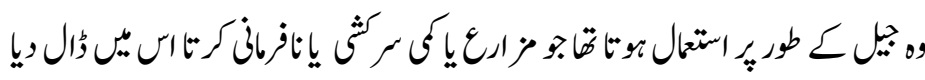

$$
\text { (ri) }
$$

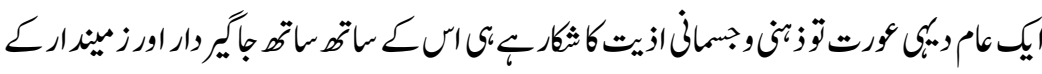

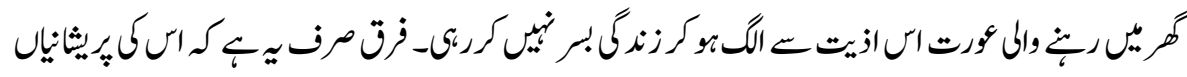

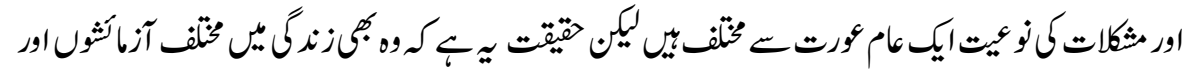

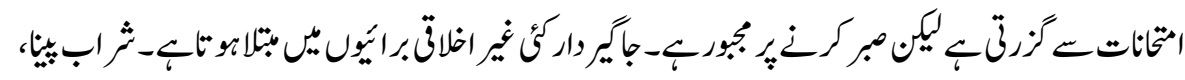

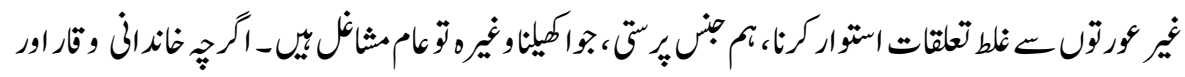

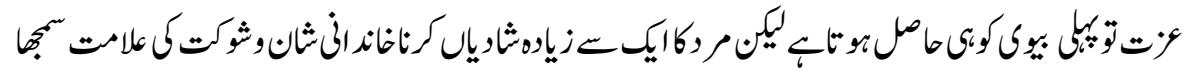

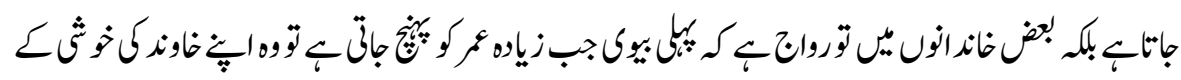

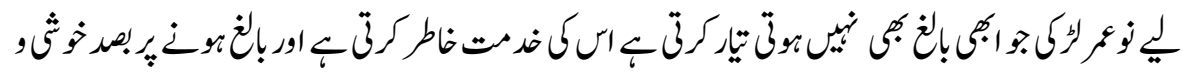

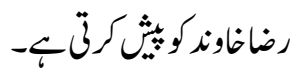

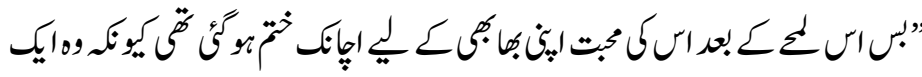

$$
\begin{aligned}
& \text { adolescence }
\end{aligned}
$$

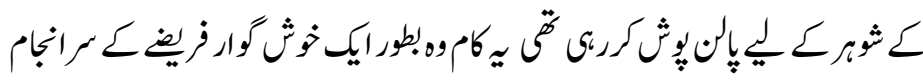




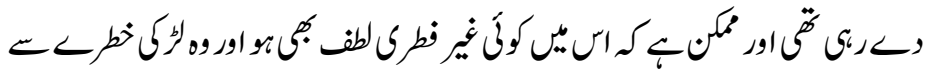

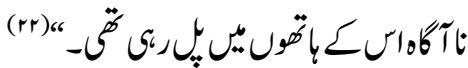

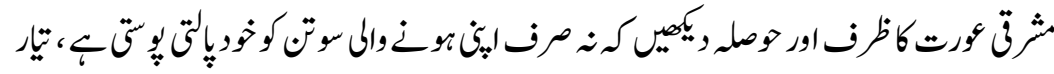

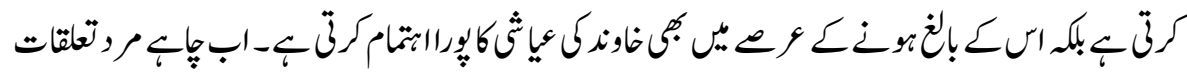

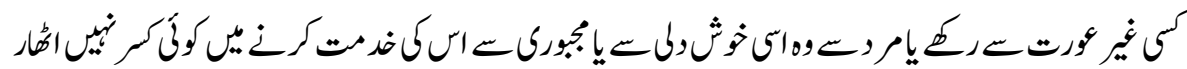

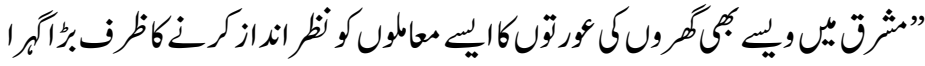

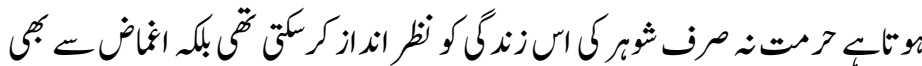

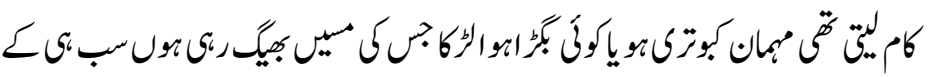

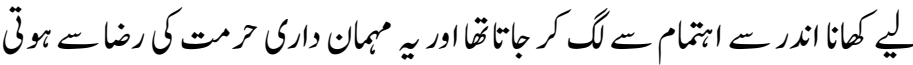

$$
\begin{aligned}
& \text { (rr) “- }
\end{aligned}
$$

"

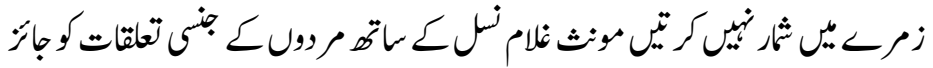

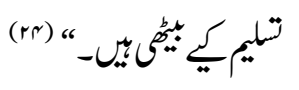

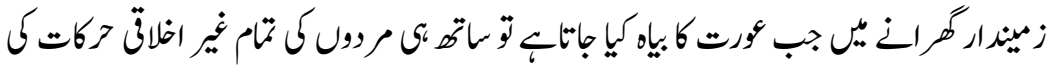

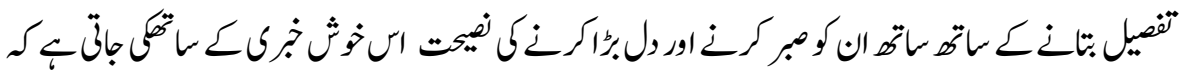

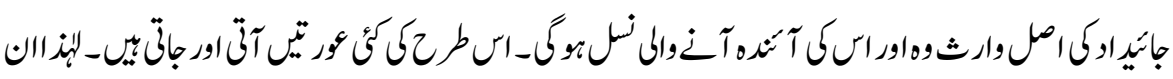

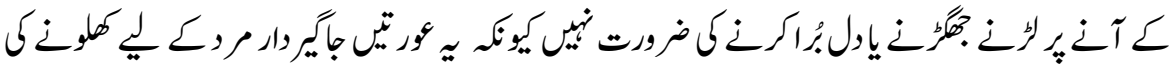

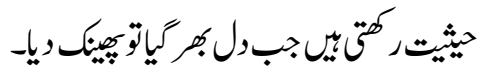

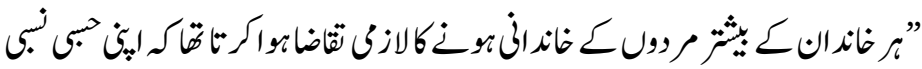

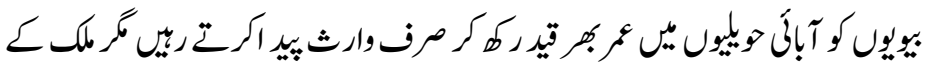

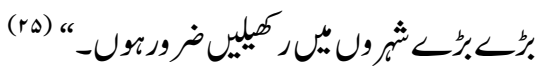


ISSN (Print): 2709-9636 | ISSN (Online): 2709-9644

Volume 2, 2021(Issue III, July to September)

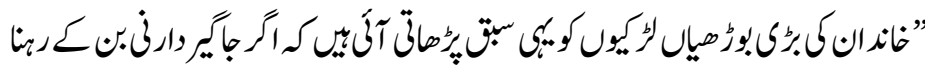

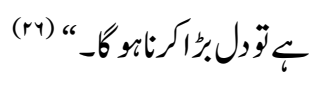

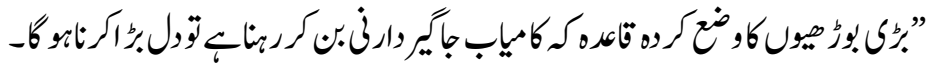

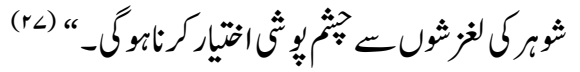

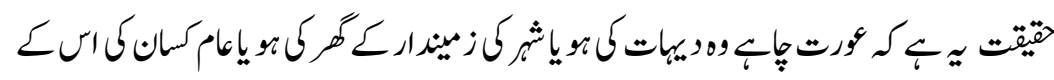

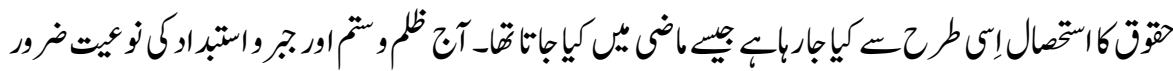

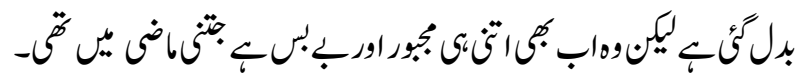
و اله جات

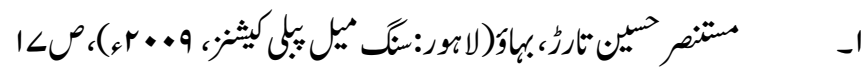

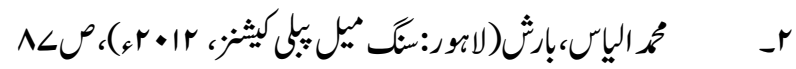

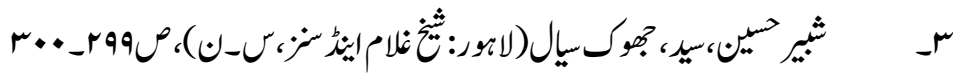

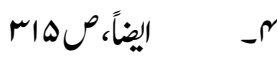

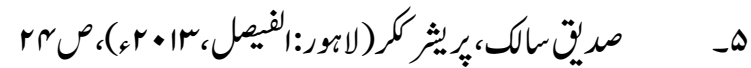

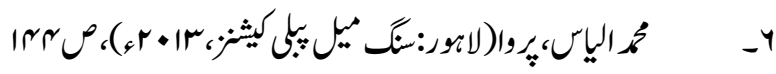

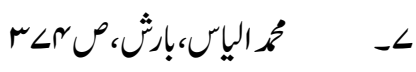

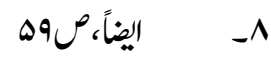

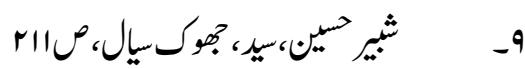

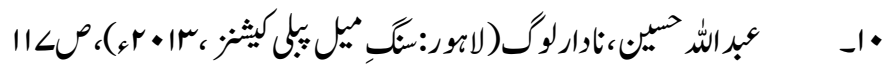

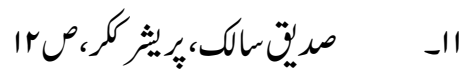

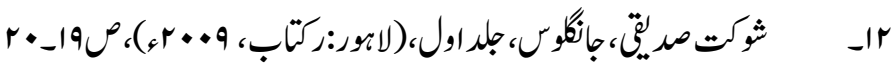

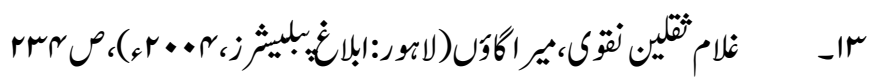

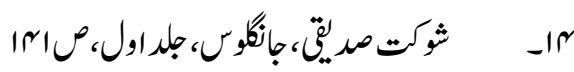

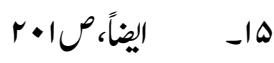




$$
\begin{aligned}
& \text { ISSN (Print): 2709-9636 | ISSN (Online): 2709-9644 } \\
& \text { Volume 2, 2021(Issue III, July to September) }
\end{aligned}
$$

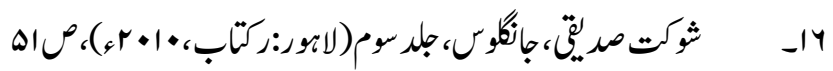

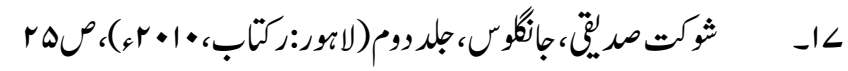

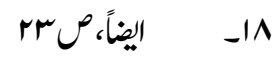

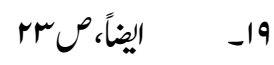

$$
\begin{aligned}
& \text { ry. } \\
& \text { ا } \\
& \text { rr } \\
& \text { r }
\end{aligned}
$$

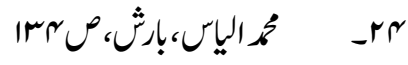

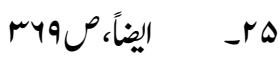

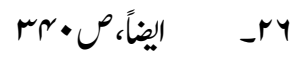

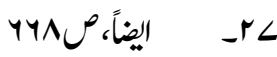

